\title{
Modeling of Lightning Strike Events, and it's Correlational with Power Outages in South-West Coast, Nigeria
}

\author{
Melodi A. O. ${ }^{1}$, Oyeleye M. O. ${ }^{2}$ \\ Department of Electrical and Electronics Engineering, Federal University of Technology, P.M.B. 704, Akure, \\ Ondo State, Nigeria
}

\begin{tabular}{l} 
Article Info \\
\hline Article history: \\
Received Nov 1, 2016 \\
Revised Nov 27, 2016 \\
Accepted Jan 5, 2017 \\
\hline Keyword: \\
Lightning strike \\
Cloud-ground flash \\
Coastal power grid \\
Power outage \\
Power outage duration \\
Power outage frequency \\
Correlation \\
Relative intensity \\
Metrological zones \\
Lightning protection
\end{tabular}

\begin{abstract}
This paper aimed to model lightning strike events and evaluate its correlation with power outages in a Nigerian power distribution system. A specified coastal distribution network of southwest Nigeria was selected as a case study. Zone-specific records of cloud-to-ground lightning strikes for 84 months were obtained from the Nigerian Meteorological Agency (NiMet); records of power outage frequencies and durations for 36 months were obtained at the substations of the selected distribution network. Using numerical statistical analysis techniques, lightning activity in the system area were characterized in relative frequency terms, and correlation statistics were evaluated and analyzed for power outages and lightning events on the $11 \mathrm{kV}$, $33 \mathrm{kV}$, and $132 \mathrm{kV}$ voltage levels. An analysis of the results shows that the modelled lightning strike events patterns are closely related but the expected frequencies vary from one zone to another; and there is correlation between lightning strike and power outages in the distribution networks, which is strong and positive at the $33 \mathrm{kV}$ and $132 \mathrm{kV}$ circuits. In essence, the results provided salient information, useful for power systems lightning protection review, management and planning in the area.
\end{abstract}

Copyright @ 2017 Institute of Advanced Engineering and Science. All rights reserved.

Corresponding Author:

Melodi A.O.,

Department of Electrical and Electronics Engineering,

Federal University of Technology,

Akure, PMB 704, Nigeria.

Email: melodiadegoke@yahoo.com

\section{INTRODUCTION}

Power system unavailability index in Nigeria is high, especially at the distribution systems. An alleged contributor to this is lightning activity or atmospheric electric discharges during thunderstorms. Over the years, numerous instances of damage to (critical) equipment were reported across a wide spectrum of systems, networks and applications in Nigeria due largely to occurrences of intense lightning activity. Generally, this study juxtaposes the lightning activity data and the power outage problem in order to establish and evaluate the links between the two in statistical and technical terms.

Theoretically, lightning strike (LS) is characterized by currents in terms of kA and ultra high temperatures. Though lightning flashes occur in the clouds, the flash between cloud and ground (LS) pose a greater challenge to PS safety. According to [1], lightning discharges are characterized by short duration of high electric voltage and current pulses. Also, lightning event is arbitrary, unpredictable and can strike anywhere on earth with current value that could exceed 40kA, induce temperature up to 50,000 degrees Fahrenheit, and move at speed closing to $33 \%$ speed of light [1],[2]. Lightning is the transient passage of electrical current between a cloud and either the surface of the earth, another cloud, or an object in or near a cloud. Lightning is most commonly associated with thunderstorms and can occur at any time and can strike anywhere on the earth surface [1],[3],[4]. According to [5], primarily, lightning occurs either within a large 
cumulonimbus cloud (cloud-to-cloud, C-C) or between the cloud-to-ground (C-G); secondarily, it occurs from ground-to-sky (G-S).

In [6], thunder storm occurrence is considered as varying with location. If these lightning pulses are not effectively discharged to the ground, they usually result in loss or damage of valuable equipment or power systems, and even loss of human life. Such objects are protected by installing protective devices that arrest LS either directly or indirectly based on principles of atmospheric electrostatic discharges and surge modification. The C-G has the greatest effects on electrical systems and its statistics of occurrence, correlation with power outages on coastal power distribution systems are the scope of this study.

Lightning strikes, especially $\mathrm{C}-\mathrm{G}$, has continued to be subject of studies in different locations and conditions as depicted in [2],[5],[7]-[9]; especially as it impacts protective grounding designs and locations; empirical intensities, physical processes in different geographical locations have been the foci. These mostly location specific foci and approaches are particularly central for sub-saharan Africa studies, where dependence on foreign models and technologies are predominant.

An earlier study on Nigeria southwest coast, [5], reported on C-G lightning strike frequency with respect to periods of the year, which was generalized for the entire southwest coast without consideration for subregion-specific data. Also, there were no specific relations established with respect to power supply and installations. However, it was assumed that lightning related faults would be expectedly high during the peak periods of lightning events in the year.

Lightning data is relevant for evaluation of the performance of protection designs [10]; and can also be used to generate variation of annual lighting stroke frequency and annual variation of number of thunderstorm day [11]. These are applicable to power systems objects and location considered in this paper; owing to the huge costs of equipment and power failures and danger on $11-132 \mathrm{kV}$ power lines, protective devices on power installations need to be evaluated in terms of standard requirement and efficacy.

The coastal regions of Nigeria are subjected to thunderstorms originating from Atlantic Ocean currents, hence they are all prone to intense lightning activities, $15 \mathrm{flash} / \mathrm{km}^{2} / \mathrm{yr}$ [5], [12]. Lagos State of Nigeria is located in the southwest coast at $6^{\circ} 35^{\prime} \mathrm{N} 3^{\circ} 45^{\prime} \mathrm{E}$; and its land area is $3474 \mathrm{~km}^{2}$ [13]. Based on LS data from Nigeria Meteorological Agency (NiMet), the State is divided into three zones: Marine (Victoria Island, Lekki, Epe and Ikorodu towns; over 2,000km²), Lagos Roof (Mainland; $19 \mathrm{~km}^{2}$ ), and Ikeja $\left(46 \mathrm{~km}^{2}\right.$ ) zones. Thes zones are denoted Z1, Z2, and Z3 respectively. Figure 1 presents a sketch of Southwest coast or Lagos region showing the three metrological zones. In addition, Lagos State consumes 43-52\% of the National power company's power output [14]. It is distinctly marked by the relatively high density of infrastructure comprising HV power transmission substations, heavy industries, numerous communication networks, the sea and reports of residents on damage to appliances due to lightning strike in this region.

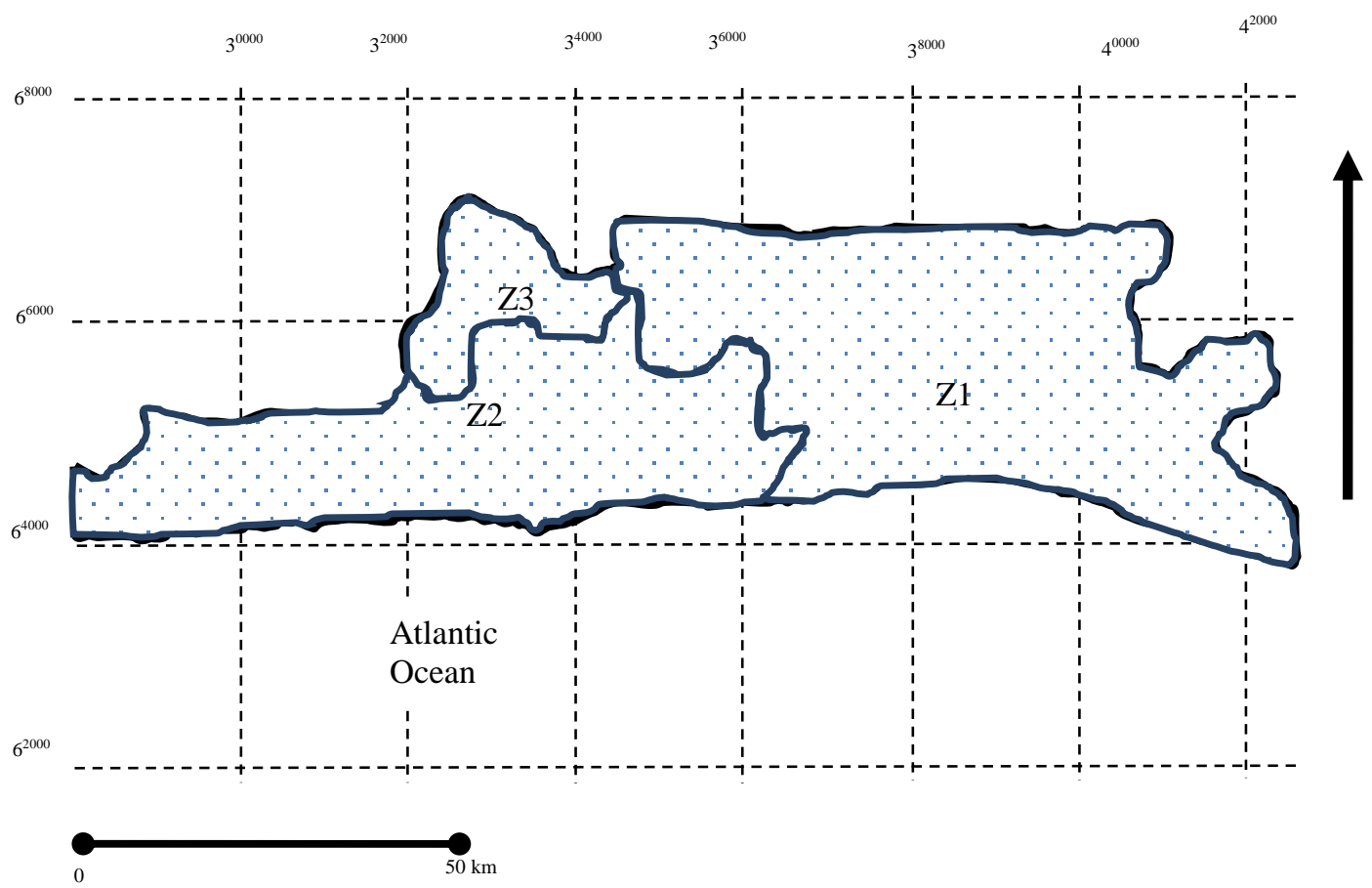

Figure 1. A Sketch of Southwest Coast showing three Metrological Zones (Z1-Z3) 
Consequent on the above, this study aimed to model C-G LS events for the coastal region using new data, and to to evaluate the correlation of LS events and power outage in the $11-132 \mathrm{kV}$ distribution systems of Nigeria using specified installations in Z1 of the coastal region as case study. For the purpose of this study, Z1's Ikorodu Transmission Substation (ITS) and distribution substation (IDS) records were applied. region.

Figure 2 illustrates connection structure of $11-132 \mathrm{kV}$ systems and exposure to thunderstorms in the

The ITS, commissioned in 1976, feeds three $132 \mathrm{kV}$ delivery stations in the zone including the IDS. The IDS feeds the township distribution networks. Over a period of 35 years, the ITS capacity grew from $2 \mathrm{x}$ 15MVA (1976) to 3 x 60MVA (2011). The ITS shares 220MW among its average 400MW power requirement by its customers. The IDS feeds 13 lines with $684 \times 11 / 0.4 \mathrm{kV}$ distribution transformers (DTs) and 5 lines with $10 x 33 / 11 \mathrm{kV}$ substations. The power supplied grew from 20MW (2007) to 30MW (2010) and $55 \mathrm{MW}$ (2012). From the operators' experiences, observed problems include frequent tripping of feeders, lightning events and faults (particularly recent serious instances), falling of tree on line pole damages, earthing failures, disc and pot shattering, and transformer damages; transformer damages were severe in wet season than in dry season. This is similar to other cases in the region.

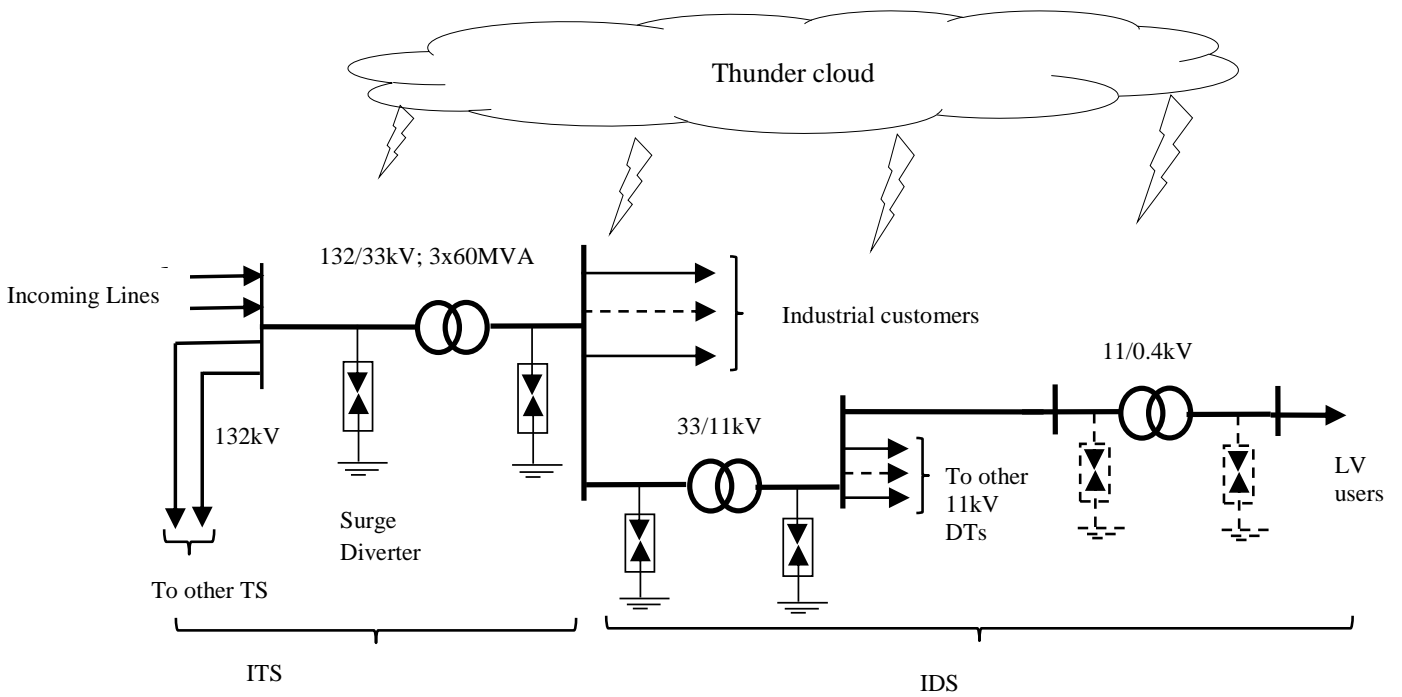

Figure 2. Connection Structure of Z1's Ikorodu Transmission and Distribution Substations Network

Revenue from electricity is basically the product of unit energy consumed and kWhr cost of energy. In order to know the approximate monthly revenue that is obtainable from a transmission substation as in Figure 2 and that would be lost due to outage, Equation (1) is applied.

$$
\mathrm{R}_{\mathrm{m}}=\mathrm{c}_{\mathrm{o}} \mathrm{P}_{\mathrm{d}} \mathrm{T}_{\text {mav }} \mathrm{LF}=\mathrm{kc}_{\mathrm{o}} \mathrm{P}_{\mathrm{d}} \mathrm{T}_{\mathrm{a}} \mathrm{LF}=\mathrm{kc}_{\mathrm{o}}\left(\mathrm{P}_{\mathrm{add}}-\mathrm{P}_{\mathrm{sdd}}\right) \mathrm{T}_{\mathrm{a}} \mathrm{LF}
$$

where $R_{m}$ is monthly revenue, $\mathrm{k}$ - time (duration) reduction factor $(\mathrm{k}=0.083) ; \mathrm{c}_{\mathrm{o}}$-cost of unit energy supplied, $\mathrm{N} / \mathrm{kWh} ; \mathrm{P}_{\mathrm{d}}$ - average peak power supplied daily, $\mathrm{T}_{\mathrm{mav}}$ - average $\mathrm{hr}$. in a month, $\mathrm{T}_{\mathrm{a}}$-hour in a year (8960), $\mathrm{P}_{\text {add }}-$ actual peak demand per day, $\mathrm{P}_{\text {sdd }}$ peak supply deficit per day, $\mathrm{LF}$ is load factor (approx.. 0.9). Monthly revenue loss due to supply deficit or suppressed demand, $R L_{m}$ :

$$
\mathrm{RL}_{\mathrm{m}}=\mathrm{kc}_{\mathrm{o}} \mathrm{P}_{\text {sdd }} \mathrm{T}_{\mathrm{a}} \mathrm{LF}
$$

Potential monthly revenue due to actual system demand $\left(\mathrm{R}_{\text {pot.(m) }}\right)$ :

$$
R_{\text {pot. }(m)}=R_{m}+R L_{m} \text {, }
$$

$\mathrm{R}_{\mathrm{m}}, \mathrm{RL}_{\mathrm{m}}$, and $\mathrm{R}_{\text {pot.(m) }}$ were evaluated for the selected ITS-IDS and shown in Table 1. 
Table 1. Estimates of $R_{m}$ and $R L_{m}$ (at $c_{o}=24.08$, naira $\left./ \mathrm{kWHr}\right)$

\begin{tabular}{|c|c|c|c|c|c|c|c|c|c|c|}
\hline Object & $\mathrm{P}_{\mathrm{d}} \mathrm{MW}$ & $\mathrm{T}_{\mathrm{a}}, \mathrm{hr}$ & $\begin{array}{c}\mathrm{C}_{\mathrm{O}}, \\
\text { naira/kWHr }\end{array}$ & $\begin{array}{l}\mathrm{P}_{\text {add }} \\
\text { MW }\end{array}$ & $\begin{array}{l}\mathrm{P}_{\text {sdd }} \\
\text { MW }\end{array}$ & k & $\mathrm{LF}$ & $\mathrm{R}_{\mathrm{m}}$, naira & $\mathrm{RL}_{\mathrm{m}}$, naira & $\mathrm{R}_{\text {pot.(m) }}$, naira \\
\hline
\end{tabular}

The $\mathrm{RL}_{\mathrm{m}}$ value for ITS is approximately 2.85 billion naira. This $45 \%$ monthly revenue loss due to prevailing inadequate supply capacity is very large and should not be aggravated by outages due to atmospheric factor as lightning. The cost of 4 x 60MVA transformers alone in $132 / 33 \mathrm{kV}$ substation is 1.8 billion. As earlier indicated, the considered coastal regions lie in the tropics and are subjected to intense thunderstorms [5]; consequently, power installations are prone to lightning incidences in the region. Therefore, protection of apparent capital intensive electric power network installations and systems operations reliability will mitigate costs and save huge revenue.

\section{RESEARCH METHOD}

In order to model C-G LS events for the coastal region using new data, C-G LS records (2006-2012) for the specified coastal area were considered and obtained from the Nigerian Metrological Agency (NiMet). A survey of installations shows unavailability of LS counter records. Therefore, to obtain the correlation of LS events and power outage in the $11-132 \mathrm{kV}$ systems, outage data for $11-132 \mathrm{kV}$ power supply stations and associated lines in a metrological zone of the area (i.e., Z1) were extracted from respective stations' records; and evaluated for correlation with obtained zonal C-G LS records, using inferential statistical concepts (relative frequency and correlational statistical techniques) [15]. The algorithm was implemented with proprietary MS-Excel software.

\subsection{Relative Intensity Statistic}

Relative intensity of C-G LS for each month of the year was evaluated in terms of relative lightning frequency. Relative lightning frequency for a given zone $(\mathrm{z})$, month $(\mathrm{m})$, and year $(\mathrm{y})$ was defined and evaluated as $R L F_{m}^{(Z)}$ using:

$$
R L F_{m}^{(Z)}=\frac{\sum_{y=1}^{7} Q L S_{m, y}^{(Z)}}{\sum_{y=1}^{7} Q L S_{y}^{(Z)}}
$$

where $Q L S_{m, y}^{(Z)}$ - quantity of C-G LS for given zone, month, and year; and $Q L S_{y}^{(Z)}$ - quantity of C-G LS for given zone and year. The values for $Q L S_{m, y}^{(Z)}$ and $Q L S_{y}^{(Z)}$ were obtained from NiMet records for 2006 to 2012 years. The values obtained for $R L F_{m}^{(Z)}$ are presented in Figure 3 and analysed.

\subsection{Zonal and Monthly Probabilities of C-G LS Event}

Probability of C-G LS event for a given zone $(\mathrm{Z})$ and month was defined and evaluated as $P(Z)\left(L S_{m}>n\right)$ using:

$$
P^{(z)}\left(L S_{m}>n\right)=\frac{q^{(z)}\left(L S_{m}>n\right)}{q^{(z)}\left(L S_{m}\right)} ; n=(0,1,2)
$$

where $q^{(z)}\left(L S_{m}>n\right)$ is quantity of LS events greater than $\mathrm{n}$, and $q^{(z)}\left(L S_{m}\right)-$ qty. of LS events in month $\mathrm{m}$ for the entire data period. Values obtained for $P\left(L S_{m}>n\right)$ are presented in Figures 4 to 6 and analysed for $n$ $=(0,1,2)$ and profiles the probability of LS in each of the month of a year for the study zones.

\subsection{Zonal and Monthly Average and Range Statistics of LS Events}

The monthly and annual averages of $L S, A L S_{m}$ and $A L S_{Y}$ respectively, were evaluated as in:

$$
A L S_{m}=\frac{\sum_{y=1}^{Y} L S_{m, y}}{Y} ; Y=7
$$

where $L S_{m, y}$-lightning strike events in given month and year y; Y - number of years y in data period. Average annual LS events for the data period: 


$$
A L S_{Y}=\frac{\sum_{y}^{Y} A L S, y}{Y} ; A L S_{y}=\sum_{m} A L S_{y, m}
$$

where $A L S_{y}$ - average LS event for year y, $A L S_{y, m}$ is average LS for given year and month. Results of $A L S_{m}, A L S_{y}$ are presented in Figures 7 to 9.

\subsection{Correlation Analysis Of C-G LS And Outage Data}

Data of power outage durations on $11 \mathrm{kV}, 33 \mathrm{kV}$, and $132 \mathrm{kV}$ lines were extracted from system daily records and summarized for each of the three years. Correlation between these data and corresponding data on C-G LS events were evaluated correlation function as in MS Excel (2013):

$$
\operatorname{Correl}\left(P O_{y, m}, L S_{y, m}\right)=\frac{\sum\left(P O_{y, m}-A P O_{y}\right)\left(L S_{y, m}-A L S_{y}\right)}{\sqrt{\sum\left(P O_{y, m}-A P O_{y}\right)^{2} \sum\left(L S_{y, m}-A L S_{y}\right)^{2}}}
$$

where $P O_{y, m}$-power outage for a particular year and particular month; $A P O_{y}$-average power output for corresponding year; $L S_{y, m}$-Lightning strike for a particular year and particular month. The result is presented in Table 2 .

\section{RESULTS AND ANALYSIS}

Results obtained from evaluation of $\mathrm{C}-\mathrm{G}$ lightning st rike in study location and correlation with power outages on 11-132 kV network are as in Figures 3 to 9 and Table 2. Figure 3 presents monthly RLFs of zones Z1 to $\mathrm{Z} 3$ respectively. Figures 4 to 6 present the monthly probabilities of LS in the three mentioned zones respectively. Analogically, Figures 7 to 9 present the monthly and annual LS averages for the same zones.

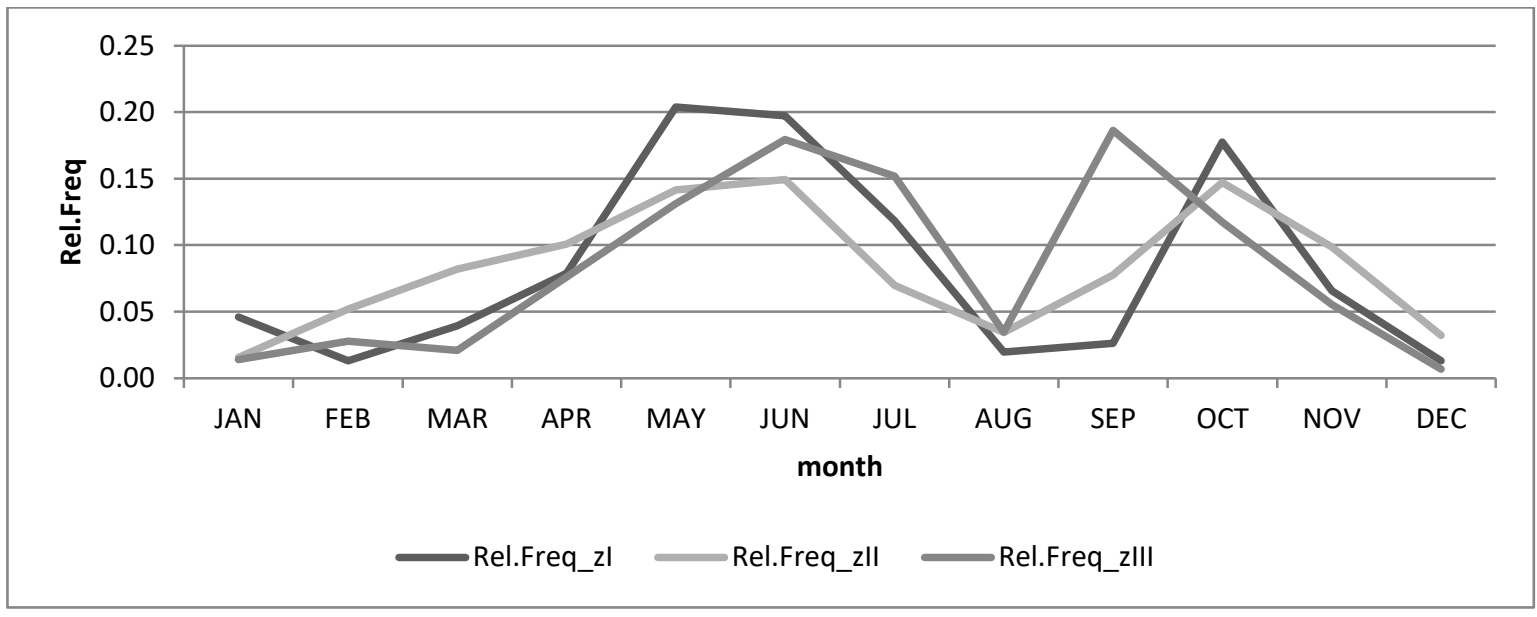

Figure 3. Obtained Monthly RLFs for Zones 1 to 3, Lagos State, southwest coast, Nigeria

Figure 3 values for zone Z1 show that LS events can be expected throughout the year. However, the intensity varies: 0-5\% of annual total of LS is expected in 5 months of every year: January to March; August to September; and December. These include dry season and rain break months for the region. More LS events are expected April, July, and November. Figure 3 further shows that RLF variation patterns for Z2 and Z3 are similar to that of $\mathrm{Z} 1$ but vary in magnitudes. Also, the peak for $\mathrm{Z} 1$ comes a month earlier. The highest magnitude is in June; while for the other zones it can be expected in both May and June.

Figure 4 to 6 presents monthly probabilities of three categories of LS frequencies: LS>0; LS>1; and LS>2. It is notable in Figure 4 that for zone Z1, the probability of LS event exceeding twice in February, March, August, and September, is nil. Figure 6 shows that zone Z3 has the highest probabilities of higher (>2) LS frequencies for all months. 


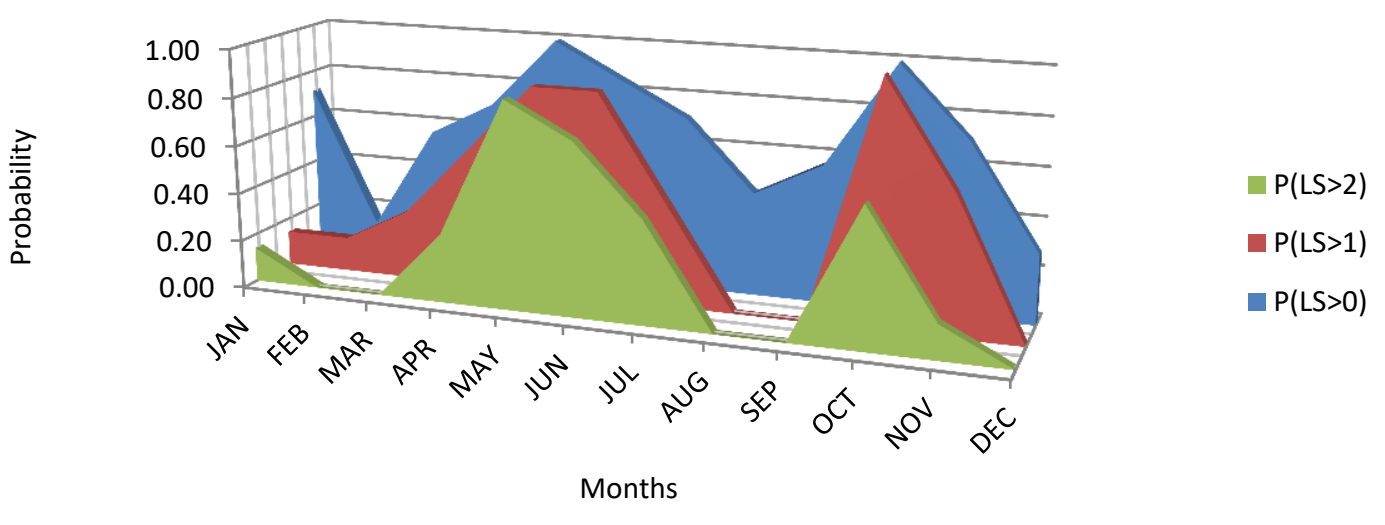

Figure 4. Monthly Probabilities of LS occurring at least once (LS>0); twice (L>1); and thrice $L S>2$ ) in Zone Z1

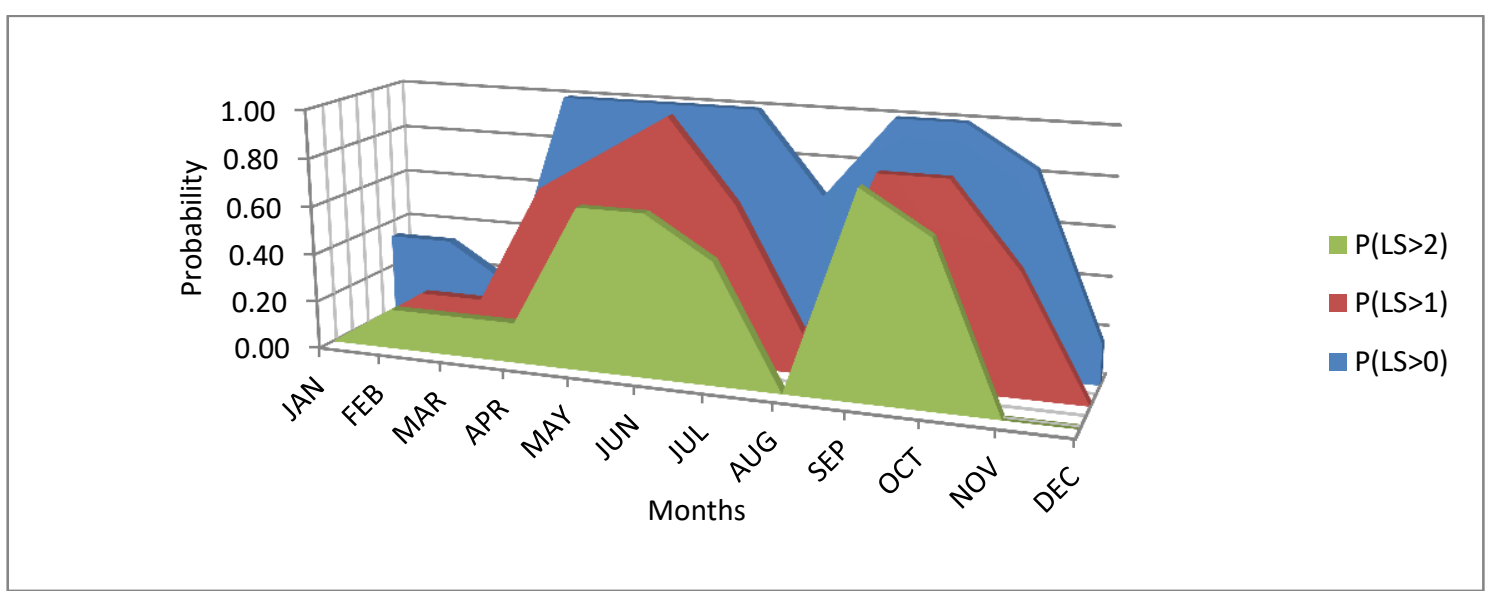

Figure 5. Probability of LS occurring at least once (LS>0); twice $(\mathrm{L}>1)$; and thrice $\mathrm{LS}>2$ ) in in Zone Z2

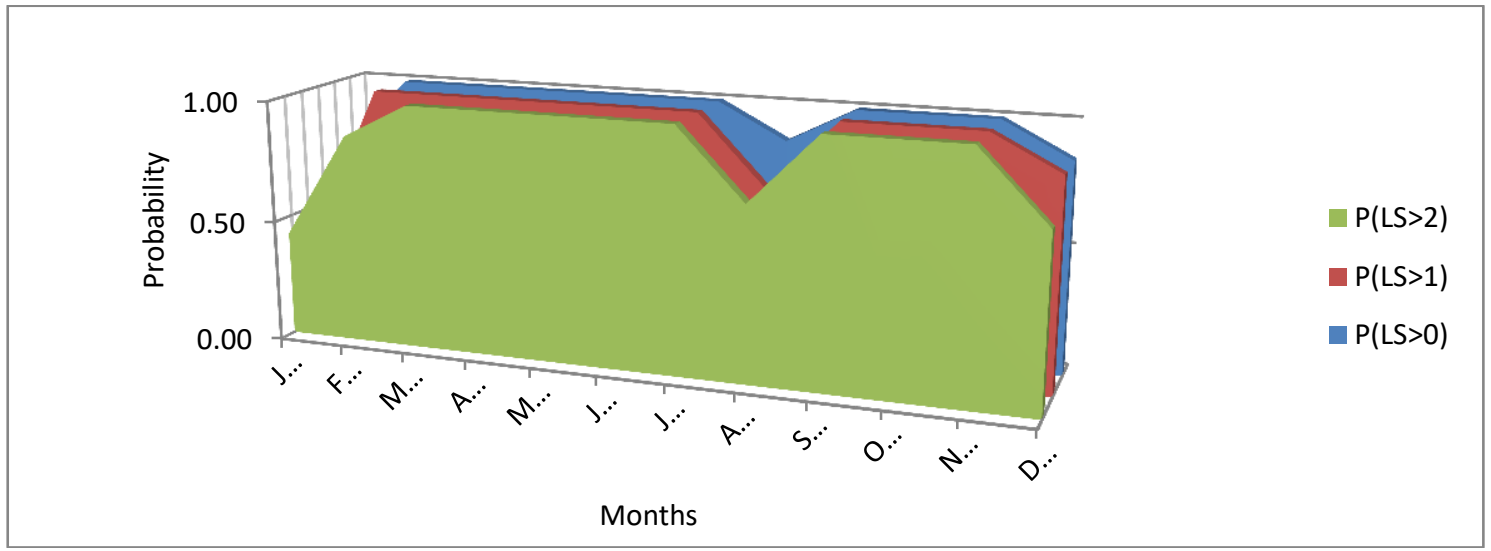

Figure 6. Probability of LS occurring at least once (LS>0); twice $(\mathrm{L}>1)$; and thrice $\mathrm{LS}>2)$ in in Zone $\mathrm{Z3}$

Figure 7 to 9 show that: for zone $\mathrm{Z1}, \mathrm{ALS}_{\mathrm{m}}$ can range from 1 to 7 events per month, with peak expected in June; for zone $\mathrm{Z} 2, \mathrm{ALS}_{\mathrm{m}}$ can range from 1 to 6 events, with peak expected in June, July, and September; and for zone $\mathrm{Z} 3, \mathrm{ALS}_{\mathrm{m}}$ can range from 4 to 22 events, with peak expected in June and October. Annualy, ALS $\mathrm{y}_{\mathrm{y}}$ can have the following monthly ranges: $(11,27)$ events, $(11,31)$ events, and $(81,145)$ events for zones $\mathrm{Z1}, \mathrm{Z} 2$, and Z3 
respectively. These values ascertained that lightning intensity varies from one location to another location. The seasonality should be considered when planning annual maintenance strategies of protective installations.

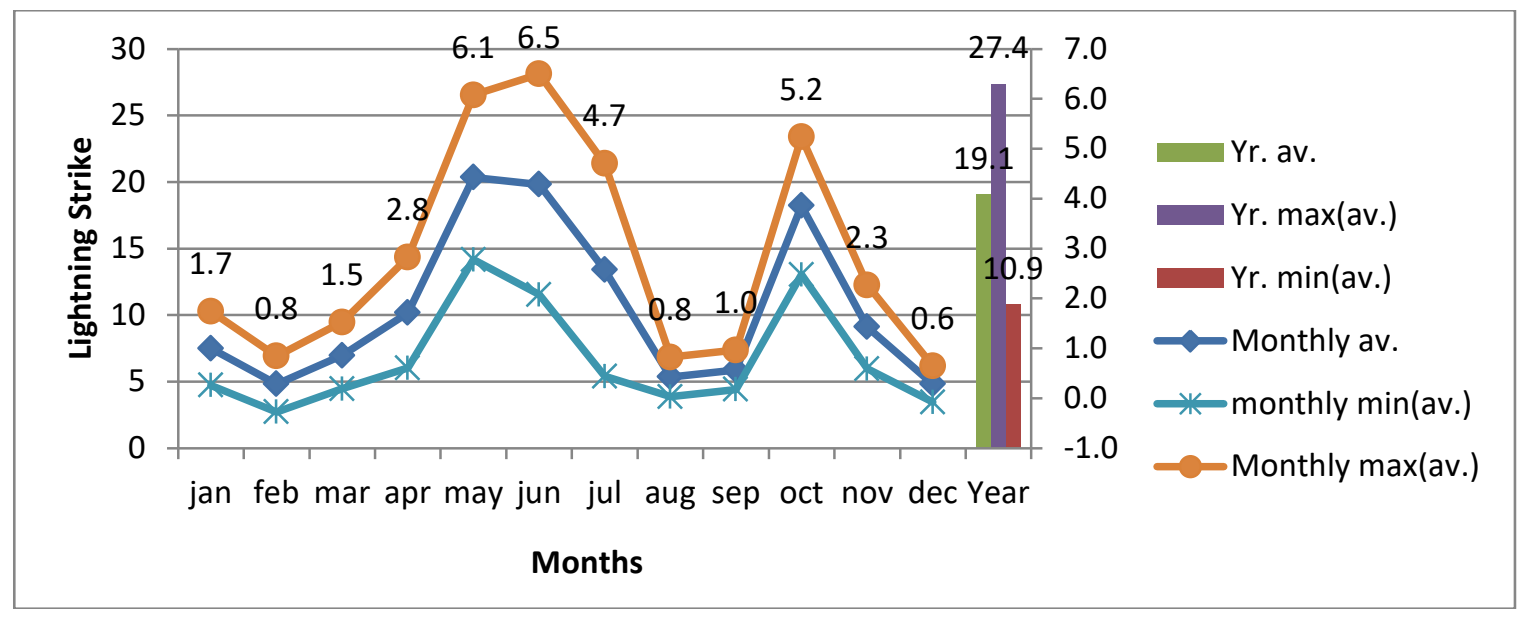

Figure 7. Monthly Average LS“ strike in Zone Z1

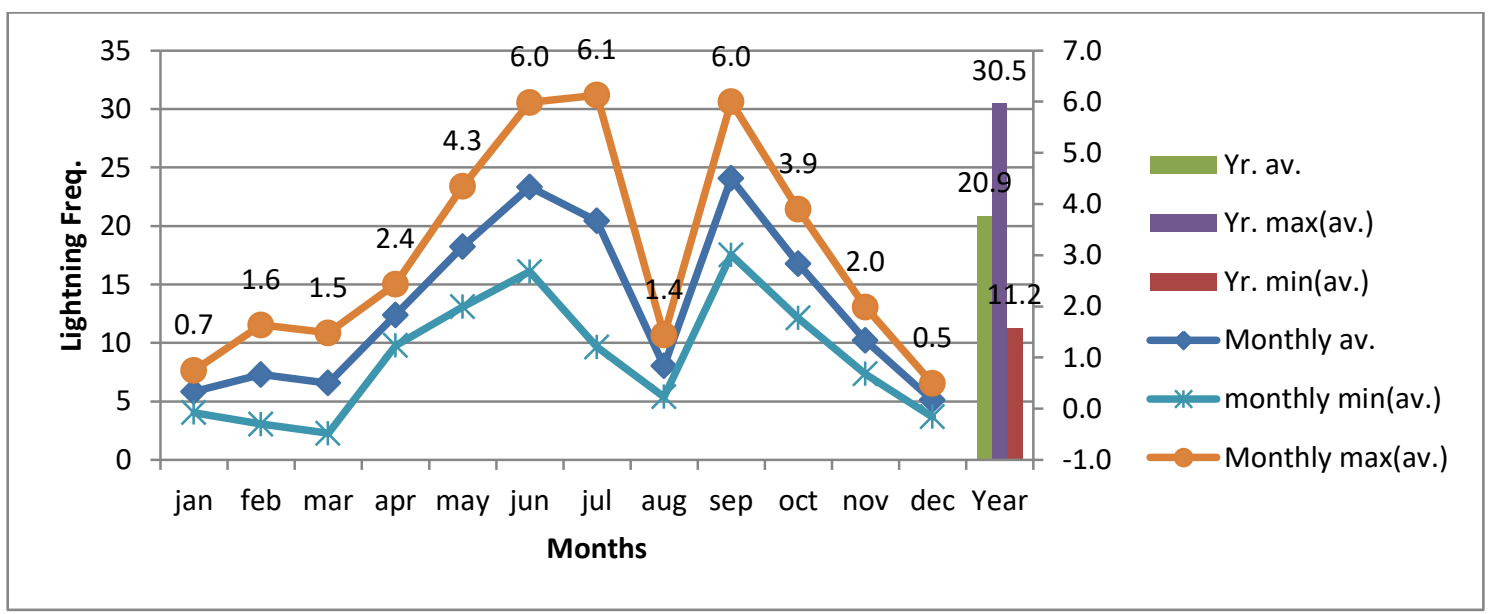

Figure 8. Monthly Average LS strike in Zone Z2

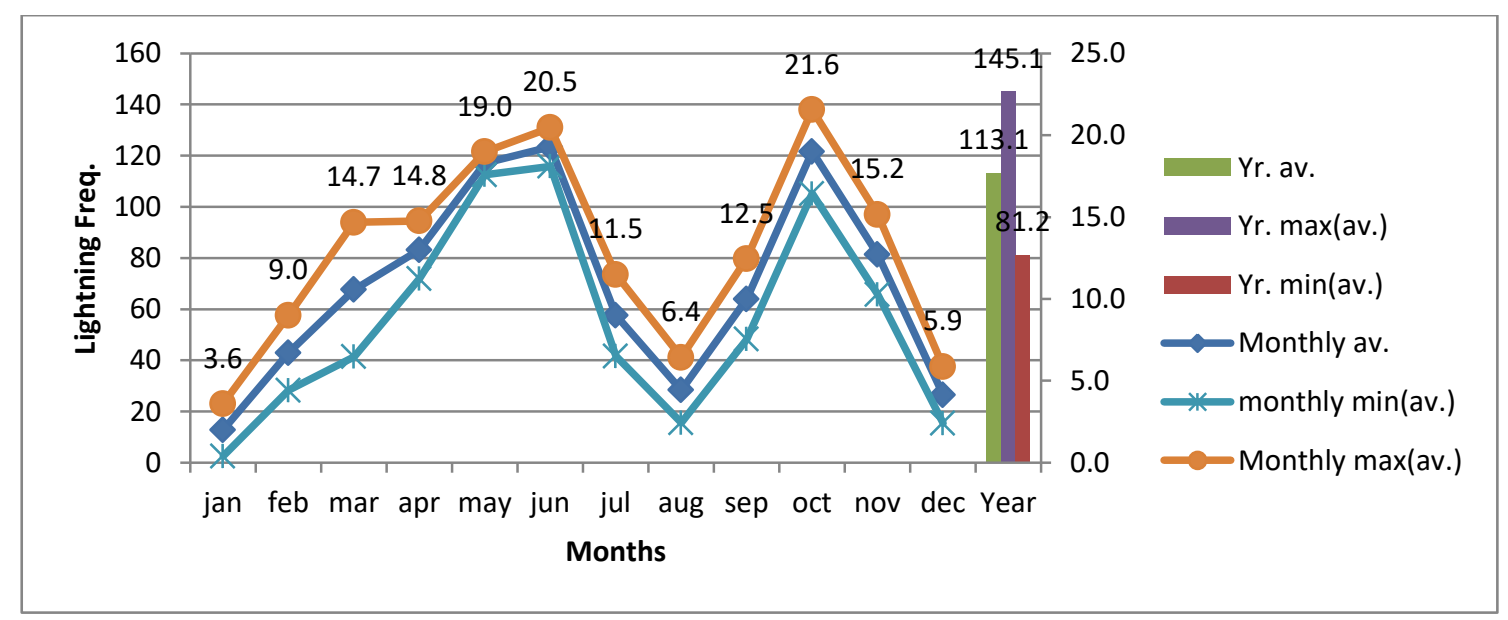

Figure 9. Monthly Average LS strike in Zone Z3 
Generally, these values and analyses, depicted by Figures 4 to 10 , indicate that C-G LS intensity is significant in the study location and adequate measures should be developed to curtail them for the power installations. This justifies a need to investigate the adequacy of existing LPS installations.

Table 2 shows that correlation between C-G LF and power outage duration in zone Z1 (Ikorodu) is: weakly positive for $11 \mathrm{kV}$ installations (0.08-0.39); strong and positive for $33 \mathrm{kV}$ installations $(0.45-0.85)$; and moderately positive for $132 \mathrm{kV}$ installations $(0.3-0.55$, in 2012). These values generally show that the relationships between LS and PO are positive linear relationships, being strongest in 33 and $132 \mathrm{kV}$ systems. In addition, Table 3 shows that the correlation outcome between C-G LF and outage frequency is equally significant for $33 \mathrm{kV}$ and 132 $\mathrm{kV}$ installations. This observation indicates that the existing lightning protective schemes are unreliable and validates a need to evaluate the active efficiency of existing lightning protection schemes on the PDNs in the coastal area, and by extension, Nigeria.

Table 2. Correlation for C-G LF and Power Outage Events Duration on $11 \mathrm{kV}, 33 \mathrm{kV}$ and $132 \mathrm{kV}$ Systems, 2010-2012

\begin{tabular}{|c|c|c|c|c|c|c|c|}
\hline \multirow{2}{*}{ System } & \multicolumn{3}{|c|}{ Correlation Coeffiscients } & \multicolumn{3}{|c|}{ p-values (at alpha $=0.05$ ) } & \multirow{2}{*}{ Correlation Status and Significance } \\
\hline & 2010 & 2011 & 2012 & 2010 & 2011 & 2012 & \\
\hline $11 \mathrm{kV}$ & 0.08 & 0.23 & 0.39 & 0.79664 & 0.46975 & 0.21227 & weak \& insignificant $()$, \\
\hline $33 \mathrm{kV}$ & 0.45 & 0.85 & 0.70 & 0.13789 & 0.00050 & 0.01148 & strong positive \& significant $(, 2011,2012)$ \\
\hline $132 \mathrm{kV}$ & 0.30 & 0.47 & 0.55 & 0.34148 & 0.12582 & 0.06498 & moderate positive \& insignificant $(,)$, \\
\hline
\end{tabular}

Table 3. Correlation for C-G LF and Power Outage Events Frequency on $11 \mathrm{kV}, 33 \mathrm{kV}$ and $132 \mathrm{kV}$ Systems, 2010-2012

\begin{tabular}{cccccccc}
\hline \multirow{2}{*}{ System } & \multicolumn{3}{c}{ Correlation Coeffiscients } & \multicolumn{3}{c}{ p-values (at alpha $=0.05)$} & \multirow{2}{*}{ Correlation Status and Significance } \\
& 2010 & 2011 & 2012 & 2010 & 2011 & 2012 & No data available \\
\hline $11 \mathrm{kV}$ & - & - & - & - & - & - & Strong positive \& significant(2010,2012) \\
$33 \mathrm{kV}$ & 0.93 & 0.54 & 0.70 & 0.000012 & 0.072539 & 0.011680 & Moderate positive \& significant $(, 2011,2012)$ \\
$132 \mathrm{kV}$ & 0.36 & 0.62 & 0.68 & 0.252851 & 0.031330 & 0.015534 & \\
\hline
\end{tabular}

\section{CONCLUSION}

The focus of this paper has been on obtaining model quantitative values and patterns for C-G LS events useful for system design, planning, and maintenance schedules; and to establish a possible correlation with incessant power outages in the specified coastal region, which should be factored-in in the critical search for power outage mitigating measures in present Nigeria systems. From the analyses of the results, it is ascertained that lightning strikes vary from one location or zone to the other. LS events are significantly intense in the studied region and contribute to power outage at $11-132 \mathrm{kV}$ installations. Model range values of C-G LS events is $(11,145)$ events per month. $33 \mathrm{kV}$ and $132 \mathrm{kV}$ installations have the highest correlation of outage with LS events in the region. $11 \mathrm{kV}$ installations are weakly correlated, indicating that other factors are more salient contributors to outages at this level. Graphical and numerical models of C-G LS events are provided for application in planned LPS installation and maintenance for Nigerian southwest coast. This correlation analyses of lightning events and power outages in 11-132kV networks along Nigerian coast establish the degree of lightning disturbances on power availability and by implication, insight into the effectiveness or adequacy of existing lightning protection scheme in the system.

\section{REFERENCES}

[1] R. Kithil, "Fundamentals of Lightning Protection," National Lightning Safety Institute (NLSI), 2010.

[2] S. N. Nikolovski, et al., "Frequency and Time Response of Power Plant Grounding System Exposed to Lightning Strike," International Journal of Electrical and Computer Engineering, vol/issue: VI(2), pp. 512-525, 2016.

[3] B. S. Ronald, "Consulting on lightning damage or injury, Ph.D Thesis," 2011.

[4] C. E. Dick, "An Analysis of the impact and predictability of lightning strikes in Tallahassee, Florida," 2011.

[5] A. I. Mowete and M. A. K. Adelabu, "Assessment of lightning and other electromagnetic disturbances along the coast of south west Nigeria," XIX-th International Conference on Electromagnetic, pp. 200-203, 2009.

[6] V. Cooray, "The Lightning Flash," IEE Power and Energy, vol. 34, pp. 574-579, 2003.

[7] B. R. P. da Rocha, et al., "Lightning Characteristics Time Distribution over Four Locations in Eastern Amazonia," in IX International Symposium on Lightning Protection (IX SIPDA), Foz do Iguaçu (Brazil), 2007.

[8] J. O. Adepitan and F. O. Ogunsanwo, "Investigating the Relationship between some Thunderstorm Parameters and Ground Flash Density," The Pacific Journal of Science and Technology, vol/issue: 13(2), pp. 148-150, 2012.

[9] C. L. Wooi, et al., "Statistical Analysis on Preliminary Breakdown Pulses of Positive Cloud-to-Ground Lightning in Malaysia," International Journal of Electrical and Computer Engineering, vol/issue: VI(2), pp. 844-850, 2016. 
[10] F. A. Auditore, "Refurbishment and Upgrading Design Options-lightning Mast VersusOverhead Sheilding Conductor," in EEA Conference, 2009.

[11] S. Yakoyama, "Lightning Detection and LightningProtection of Power System in Japan Panel Paper," in IEEE PES Transmission and Distribution, Asia Pacific Yakohama, 2002.

[12] Geology.com, "World Lightning Map," 2013.

[13] O. Leke and E. Gbenga, "Effects of Global Economy on Spatial Structure of Ikeja, Lagos," in Department of Urban and Regional Planning, Faculty of Environmental Sciences, University of Lagos, Akoka., Lagos, 2013.

[14] I. O. Megbowon and T. O. Oyebisi, "A Reliability Assessment of South West Transmission Lines of the Nigerian National Grid," FUTAJEET, vol/issue: IV(1), pp. 17-22, 2005.

[15] G. Keller and B. Warrack, "Statistics for Management and Economics," Pacific Grove, USA, Thompson Learning Inc, pp. 832, 2003. 